\title{
Electrophysiological Studies of Forskolin-Induced Changes in Ion Transport in the Human Colon Carcinoma Cell Line HT-29 cl.19A: Lack of Evidence for a cAMP. Activated Basolateral $\mathbf{K}^{+}$Conductance
}

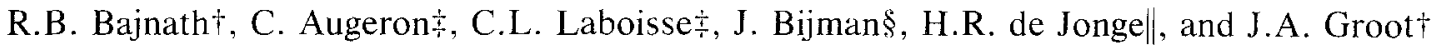 \\ †Department of Experimental Zoology. University of Amsterdam. Amsterdam. The Netherlands. $\doteqdot$ Unite 239 INSERM. Paris, \\ France, \$Department of Cellbiology, Erasmus University, Rotterdam. The Netherlands, and \|Department of Biochemistry 1. \\ Erasmus University, Rotterdam, The Netherlands
}

\begin{abstract}
Summary. Forskolin (i.e., cAMP)-modulation of ion transport pathways in filter-grown monolayers of the $\mathrm{Cl}^{-}$-secreting subclone (19A) of the human colon carcinoma cell line HT29 was studied by combined Ussing chamber and microimpalement experiments.

Changes in electrophysiological parameters provoked by serosal addition of $10^{-5} \mathrm{M}$ forskolin included: $(i)$ a sustained increase in the transepithelial potential difference $(3.9 \pm 0.4 \mathrm{mV})$. (ii) a transient decrease in transepithelial resistance with $26 \pm 3$ $\Omega \cdot \mathrm{cm}^{2}$ from a mean value of $138 \pm 13 \Omega \cdot \mathrm{cm}^{2}$ before forskolin addition, (iii) a depolarization of the cell membrane potential by $24 \pm 1 \mathrm{mV}$ from a resting value of $-50 \pm 1 \mathrm{mV}$ and (iv) a decrease in the fractional resistance of the apical membrane from $0.80 \pm$ 0.02 to $0.22 \pm 0.01$. Both, the changes in cell potential and the fractional resistance, persisted for at least $10 \mathrm{~min}$ and were dependent on the presence of $\mathrm{Cl}^{-}$in the medium. Subsequent addition of bumetanide $\left(10^{-4} \mathrm{M}\right)$, an inhibitor of $\mathrm{Na} / \mathrm{K} / 2 \mathrm{Cl}$ cotransport. reduced the transepithelial potential, induced a repolarization of the cell potential and provoked a small increase of the transepithelial resistance and fractional apical resistance. Serosal $\mathrm{Ba}^{2+}$ (1 $\mathrm{mm}$ ), a known inhibitor of basolateral $\mathrm{K}^{-}$conductance, strongly reduced the electrical effects of forskolin. No evidence was found for a forskolin (cAMP)-induced modulation of basolateral $\mathrm{K}^{-}$ conductance.

The results suggest that forskolin-induced $\mathrm{Cl}^{-}$secretion in the HT-29 cl.19A colonic cell line results mainly from a cAMP. provoked increase in the $\mathrm{Cl}^{-}$conductance of the apical membrane but does not affect $\mathrm{K}^{+}$or $\mathrm{Cl}^{-}$conductance pathways at the basolateral pole of the cell. The sustained potential changes indicate that the capacity of the basolateral transport mechanism for $\mathrm{Cl}^{-}$and the basal $\mathrm{Ba}^{2+}$-sensitive $\mathrm{K}^{+}$conductance are sufficiently large to maintain the $\mathrm{Cl}^{-}$efflux across the apical membrane. Furthermore, evidence is presented for an anomalous inhibitory action of the putative $\mathrm{Cl}^{-}$channel blockers NPPB and DPC on basolateral conductance rather than apical $\mathrm{Cl}^{-}$conductance.
\end{abstract}

Key Words $\mathrm{Cl}^{-}$transport $\cdot \mathrm{K}^{+}$conductance forskolin cAMP - HT-29 cl.19A - electrophysiology

\section{Introduction}

Following the introduction of a general transport model accounting for $\mathrm{Cl}^{-}$secretion by epithelial tis- sues (Frizzell, Field \& Schultz, 1979), a number of studies have provided detailed information about the nature of the transport systems and the signal transduction mechanisms involved.

In airway epithelial cells in particular, the model has been evaluated in depth using electrophysiological methods (Welsh, 1987) and here it is well established that second-messenger-operated $\mathrm{Cl}^{-}$channels in the apical membrane play a key role in transepithelial $\mathrm{Cl}^{-}$secretion. These channels provide the gateway for passive efflux of $\mathrm{Cl}^{-}$from the cell to the lumen. The necessary cellular electrochemical accumulation of $\mathrm{Cl}^{-}$is maintained by a bumetanide-sensitive $\mathrm{Na} / \mathrm{K} / 2 \mathrm{Cl}$ cotransport system in the basolateral membrane. The efflux of $\mathrm{Cl}^{-}$is electrically compensated by an efflux of $\mathrm{K}^{+}$through $\mathrm{K}^{+}$channels in the basolateral membrane. The channels appear to be regulated by extracellular signals through changes in the level of intracellular signaling molecules, e.g., cAMP and $\mathrm{Ca}^{2+}$.

In intestinal epithelial cells the presence of a similar mechanism is suggested from in vitro flux measurements and transepithelial potential and short circuit current studies with isolated intestinal epithelial sheets (Heintze, Stewart \& Frizell, 1983) and with monolayers of the colonic epithelial cell lines Caco-2, $\mathrm{T}_{84}$ and HT-29.

With $\mathrm{T}_{84}$ cells it has been shown that cAMPlinked secretagogues (e.g., VIP) increased the short circuit current, the efflux of $\mathrm{Cl}^{-}$through conductance pathways and the $\mathrm{K}^{+}$efflux through the basolateral membrane, but also the bidirectional transepithelial $\mathrm{Cl}^{-}$fluxes. (Dharmsathaphorn et al., 1985: McRoberts, Beuerlein \& Dharmsathaphorn, 1985).

Microelectrode studies with the Caco-2 cell line likewise suggest that these cells possess the cAMPdependent apical $\mathrm{Cl}^{-}$conductance (Grasset, Bernabeu \& Pinto, 1985). However, transepithelial poten- 
tial changes across these cells are transient and net $\mathrm{Cl}^{-}$flux is very small, while changes across the apical membrane seem to be steady. This suggests that the $\mathrm{Cl}^{-}$efflux is limited by $\mathrm{Cl}^{-}$influx across the basolateral membrane or by an insufficient conductance for compensating ion currents in this cell line. In contrast, sustained transepithelial and intracellular changes, induced by db-cAMP have been reported in a preliminary communication for subclone 19A of the HT-29 colon carcinoma cell line (Augeron et al., 1986).

In contrast to the original HT-29 cells, the 19A subclone is morphologically and functionally uniform (Augeron \& Laboisse, 1984) and allowed us to study ion transport modulation in the absence of complicating factors such as secretagogue-provoked nerve reflexes and paracrine cascade mechanisms. Confluent monolayers of the subclone were grown on permeable and transparent polycarbonate filters, and the effects of the cAMP agonist forskolin on the transepithelial and intracellular potential and resistances were evaluated using an equivalent electrical circuit model (Groot \& Bakker, 1988) for leaky epithelia. Our findings indicate that the apical $\mathrm{Cl}^{-}$conductance in these cells is persistently activated in response to forskolin or a cAMP analog and suggest that maintenance of the transcellular current does not require an increase in the basolateral conductance. The proposed secretion model deviates in several aspects from earlier models based on the above-mentioned studies in Caco-2, $\mathrm{T}_{84}$, rabbit colon and rat small intestinal cell types and does not corroborate the previous suggestion that during cAMP-induced $\mathrm{Cl}^{-}$secretion the basolateral conductance for $\mathrm{K}^{+}$is increased (Dharmsathaphorn et al., 1985; McRoberts et al., 1985).

\section{Materials and Methods}

\section{Cell Culture Methods}

The Ht-29 cl.19A cell line (passage number 8-30) was grown in Dulbecco's modified Eagle's medium, supplemented with $10 \%$ fetal calf serum in $25-\mathrm{cm}^{2}$ culture flasks in a humidified atmosphere of $5 \% \mathrm{CO}_{2} / 95 \%$ air. Confluent monolayers were subcultured after trypsinization and plated on rat tail collagencoated nucleopore PC filters, 13-mm diameter. (Nucleopore, Pleasanton, CA) glued to Lexan rings (Dharmsathaphorn et al.. 1985). The permeable supports were placed on top of a layer of glass beads in $30-\mathrm{mm}$ culture dishes to permit bottom feeding. The cells were plated at about $5 \times 10^{5} \mathrm{cells} / \mathrm{cm}^{2}$ and used between day 7 and 31 with the medium being replaced every 2 days. About half of the experiments were done with cells grown without antibiotics. No differences were observed with cells grown in the presence of antibiotics (penicillin: $40 \mathrm{mg} /$ liter, ampicillin: $8 \mathrm{mg} / \mathrm{liter}$, streptomycin: $90 \mathrm{mg} / \mathrm{liter}$, Sigma Chemical, St. Louis, MO).

\section{Electrophysiological Measurements}

The filters were mounted horizontally in a small Ussing-type chamber, leaving an oblong area of $0.30 \mathrm{~cm}^{2}$. The upper and lower compartments were continuously perfused using roller pumps (Buchler Instruments, Fort Lee, NJ). The solutions were maintained at $36^{\circ} \mathrm{C}$ and gassed with $5 \% \mathrm{CO}_{2} / 95 \% \mathrm{O}_{2}$. The compartments were connected through Ringer/agar bridges to $\mathrm{Ag}-\mathrm{AgCl}$ electrodes to monitor the transepithelial electrical potential. Open-circuit conditions were used throughout. Usually the upper electrode served as the common ground for transepithelial and intracellular measurements. The offset between the upper and lower electrodes was measured before and after mounting of each filter. Transepithelial electrical resistance was calculated from voltage deflections induced by a current pulse of $+10 \mu \mathrm{A}$ for a duration of $1 \mathrm{sec}$ and a negative pulse of equal strength for the subsequent $1 \mathrm{sec}$. Pulses of +50 and $-50 \mu \mathrm{A}$ were used for calculation of apical-to-basolateral resistance ratio. Corrections for the resistance of the fluid between the tips of the bridges were made. The current electrodes $(\mathrm{Ag}-\mathrm{AgCl})$ were situated in the walls of the upper and lower compartments.

\section{Apical Membrane Potentials}

Apical membrane potentials were measured with glass microelectrodes made on a Flaming Brown P-87 micropipette puller (Sutter Instrument, San Rafael. CA) from Kwik-Fil borosilicate glass capillaries of I-mm o.d. (Clarck. Electromedical Supplies. Reading, UK). The tip resistance of the electrodes, filled with $0.5 \mathrm{M}$ $\mathrm{KCl}$ and inserted in the bath solution was $100-200 \mathrm{M} \Omega$; the tip potential was about $-2 \mathrm{mV}$. Impalements were performed at an angle of about $60^{\circ}$ under microscopic control (CK2, invertedphase contrast microscope, Olympus Optical, Japan) using a Narishige MO-22 hydraulic micromanipulator mounted on a $\mathrm{M}$ 152 manipulator (Narishige Scientific Instruments, Japan). The potentials were measured with M-4A electrometer probes (W-P Instruments, New Haven, $C$ T) and recorded on a multipen recorder (Rikadenki Kogyo, Japan). The criteria for successful impalements were: abrupt negative deflection of the potential, establishment of a stable potential usually more negative than the initial potential difference for at least $2 \mathrm{~min}$, constancy in the potential deflections induced by bipolar current injections and return of the microelectrode potential to its initial value $( \pm 2 \mathrm{mV})$ when the tip was withdrawn from the cell. The effect of added chemicals was studied while the microelectrode was in the cell. This required stable intracellular potential measurements for prolonged periods. Usually it was possible to record for more than 30 min from one cell. However, some recordings were lost or ended on purpose before an experimental situation was created. These recordings of cell potential and fractional resistance were pooled to obtain the basal values for the electrical parameters.

\section{Solutions}

The standard solution had the following composition (in mM): $\mathrm{NaCl} 117.5, \mathrm{KCl} 5.7, \mathrm{NaHCO}_{3} 25.0, \mathrm{NaH}_{2} \mathrm{PO}_{4} 1.2, \mathrm{CaCl}_{2} 2.5$, $\mathrm{MgSO}_{4}$ 1.2, glucose 27.8 ( $\mathrm{pH} 7.4$ ). Low Cl-Ringer solutions were made by replacing all $\mathrm{Cl}$ except for $0.1 \mathrm{~mm}$ by gluconate. High $\mathrm{KCl}$ or $\mathrm{K}$-gluconate solutions were made by replacing the sodium salt. The effects of ethanol and DMSO as carrier solutions for forskolin and NPPB (5-nitro-2-(3-phenylpropylamino)-benzoate or DPC (diphenylamine-2-carboxylate) was checked in separate 
experiments. They were without effect in the concentrations used $(0.1 \%$ as a maximum).

Forskolin and 8-Br-cAMP were from Sigma Chemical, St. Louis, MO, and bumetanide was a gift from Leo Laboratories, Ballerup, Denmark. NPPB and DPC were a gift from Dr. R. Greger, Freiburg, Germany.

\section{Equivalent Electrical Circuit Analyses}

A conventional model (Groot \& Bakker, 1988) was used to analyze the time-dependent changes in electrical parameters with the following equations:!

$$
\begin{aligned}
R_{\mathrm{t}} & =R_{p}\left(R_{a}+R_{b}\right) /\left(R_{a}+R_{b}+R_{p}\right)=1 / G_{t} \\
f R_{a} & =R_{u} /\left(R_{a}+R_{b}\right) \\
G_{t} & =G_{p}+G_{b}\left(1-f R_{u}\right) \\
l_{\mathrm{tc}} & =l_{\mathrm{pc}}=\Psi_{t} \cdot G_{p} \\
E_{a t} & =\Psi_{a}+l_{\mathrm{tc}} R_{a l} .
\end{aligned}
$$

(If the bath resistance and filter resistance are fully compensated, the short-circuit current would be equal to $I_{\mathrm{tc}}$.)

After forskolin addition, $\Psi_{n}$ and $f R_{i l}$ changed to a new steadystate value which was maintained as long as forskolin was present. This suggests that $R_{b}$ may remain constant. By performing frequent measurement of $G_{i}$ and $f R_{u}$ we found that Eq. (3) could be solved for $G_{p}$ and $G_{b}$ in the first $20 \mathrm{sec}$ after forskolin. Equations (4) and (5) were used to obtain the time-dependent change in $I_{\text {tc }}$ and $E_{u}$.

\section{Statistics.}

All values are presented as means \pm SEM. Statistical significance was evaluated using paired or unpaired $t$ tests as appropriate.

\section{Results}

\section{Basal Values of Electrical Parameters}

The monolayers were studied between day 7 and 31 after plating on the collagen-coated filters. The results of combined measurements of transepithelial potential, resistance and intracellular potential are

\footnotetext{
'Abbreviations: $\Psi_{f}$ : transepithelial potential, basolateral side with respect to apical bath which is grounded, in $\mathrm{mV} . \Psi_{a}$ : transmembrane potential, cell with respect to apical bath, in $\mathrm{mV} . I_{\mathrm{tc}}$, $I_{\mathrm{pc}}$ : transcellular and paracellular currents, respectively, in $\mu \mathrm{A} /$ $\mathrm{cm}^{2} . R_{l}, R_{a}, R_{b}, R_{p}$ : slope resistances of monolayer, apical membrane, basolateral membrane and paracellular pathway respectively, in $\Omega \mathrm{cm}^{2} . G_{l}, G_{a}, G_{b}, G_{p}$ : electrical slope conductances in $\mathrm{mS} / \mathrm{cm}^{2} . E_{a}, E_{b}$ : electromotive forces across the apical and the basolateral membrane, respectively, in $m V . f R_{a}, f R_{b}$; fractional resistance of apical and basolateral membrane, respectively, $\left(f R_{a}=R_{a} /\left(R_{a}+R_{b}\right), f R_{b}=1-f R_{a}\right)$.
}

Table 1. Electrical parameters of filter-grown monolayers of HT29 cl. 19A colon carcinoma cells

\begin{tabular}{lllll}
\hline & $\Psi_{l}(\mathrm{mV})$ & $\Psi_{\text {u }}(\mathrm{mV})$ & $\begin{array}{l}R_{t} \\
\left(\Omega \mathrm{cm}^{2}\right)\end{array}$ & $f R_{u}$ \\
\hline Control Ringer & $1.2 \pm 0.2$ & $-46 \pm 1$ & $119 \pm 8$ & $0.80 \pm 0.01$
\end{tabular}

The data shown represent the mean \pm SEM of 57 monolayers.

shown in Table 1. The transepithelial resistance, measured $30 \mathrm{~min}$ after mounting the filters in the chamber, varied between 20 and $262 \Omega \mathrm{cm}^{2}$ ( 57 monolayers). The spontaneous transepithelial potential varied between -3.2 and $+11 \mathrm{mV}$, and the intracellular potential varied between -20 and $-71 \mathrm{mV}$. No systematic differences in intracellular or extracellular electrical parameters were observed by varying the culture periods between 7 and 30 days. Neither did we find a relation between passage number (8-30) and electrical parameters. Surprisingly, the spontaneous potential differences did not correlate with the transepithelial resistances.

Figure 1 shows a histogram of the intracellular potentials measured in 249 cells from these monolayers. The values had a normal distribution around a mean of $46.7 \pm 0.6 \mathrm{mV}$ (median $47 \mathrm{mV}$ ). The impalements could typically be maintained for 30 min or longer.

Six monolayers with transepithelial resistances lower than $50 \Omega \cdot \mathrm{cm}^{2}$ were not used further.

\section{EFFECTS OF FORSKOLIN}

The effect of forskolin $\left(10^{-5} \mathrm{M}\right)$ on the electrical parameters was tested in 21 monolayers; the cAMP analogue, 8-Br-cAMP $\left(10^{-4} \mathrm{M}\right)$, was studied only in a few experiments. In all experiments the secretagogue was added to the basolateral perfusate while intracellular recordings were made continuously. In most experiments the effect of the washing out could also be followed. In contrast to the fast changes in electrical parameters upon addition, the withdrawal had a rather slow effect. The addition of 8-Br-cAMP or forskolin had fully comparable effects, and the results were pooled.

Figure 2 shows the time course of the change in $\Psi_{t}$ and $\Psi_{a}$ from a typical experiment. The intracellular potential, $\Psi_{a}$, depolarized and showed no signs of a repolarization in the continued presence of forskolin. The amplitude of the vertical voltage deflection of the intracellular recording, induced by transepithelial current injection, decreased strongly after addition of forskolin. In combination with the relatively small decrease of 


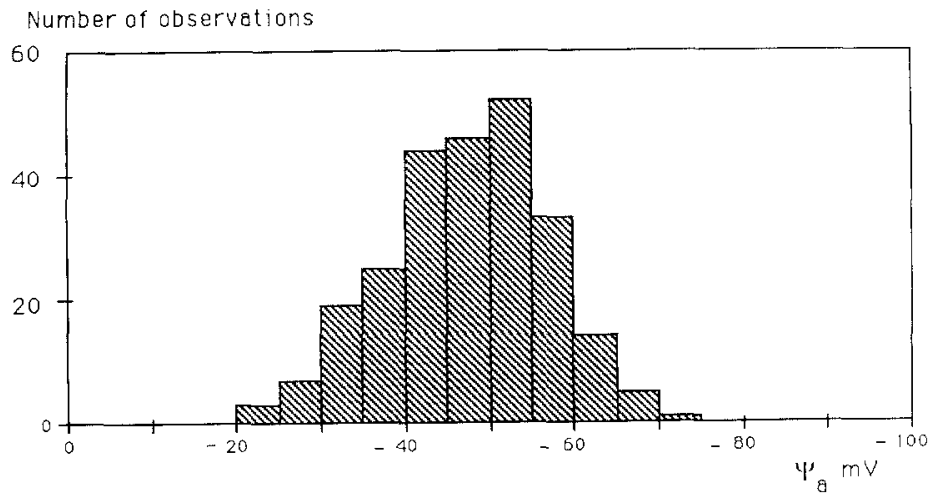

Fig. 1. Histogram of 249 individual apical membrane potentials

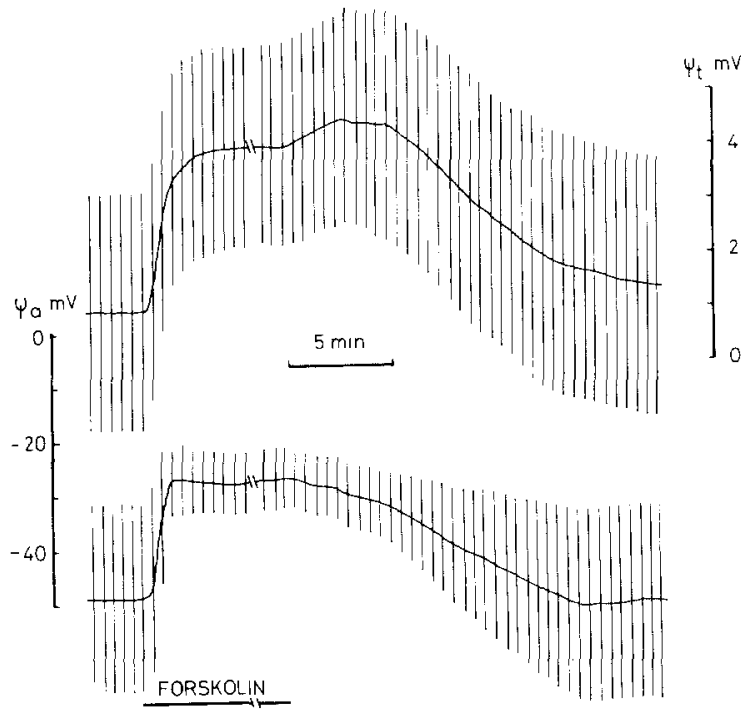

Fig. 2. Redrawn from a recording of transepithelial potential ( $\Psi_{i}$. upper tracing) and cellular potential $\left(\Psi_{a}\right.$, lower tracing) and voltage deflections induced by transepithelial current injections (10 and $50 \mu \mathrm{A}$, respectively). The bar indicates the presence of forskolin $\left(10^{-5} \mathrm{M}\right)$ in the lower compartment bathing the basolateral side. The interruption is for $10 \mathrm{~min}$

the transepithelial voltage deflections in the first 4 min, this indicates that $f R_{a}$ strongly decreased upon forskolin addition. Similar recordings were obtained in 57 other experiments.

The mean values of the electrical parameters derived just before addition of forskolin and $3 \mathrm{~min}$ afterwards are given in Table 2 . The cell potential depolarized by $26 \mathrm{mV}$, and the transepithelial potential became $4.0 \mathrm{mV}$ more positive. The mean value of $R_{t}$ just before addition of forskolin was slightly higher in this set of observations than the mean resistance of the 58 monolayers reported in Table 1 . This is partially because we selected the monolayers with transepithelial resistances higher than $50 \Omega \mathrm{cm}^{2}$. The acute effect of forskolin was always a decrease of $R_{t}$ (see Table 1), but in some monolayers, $R_{t}$ started to

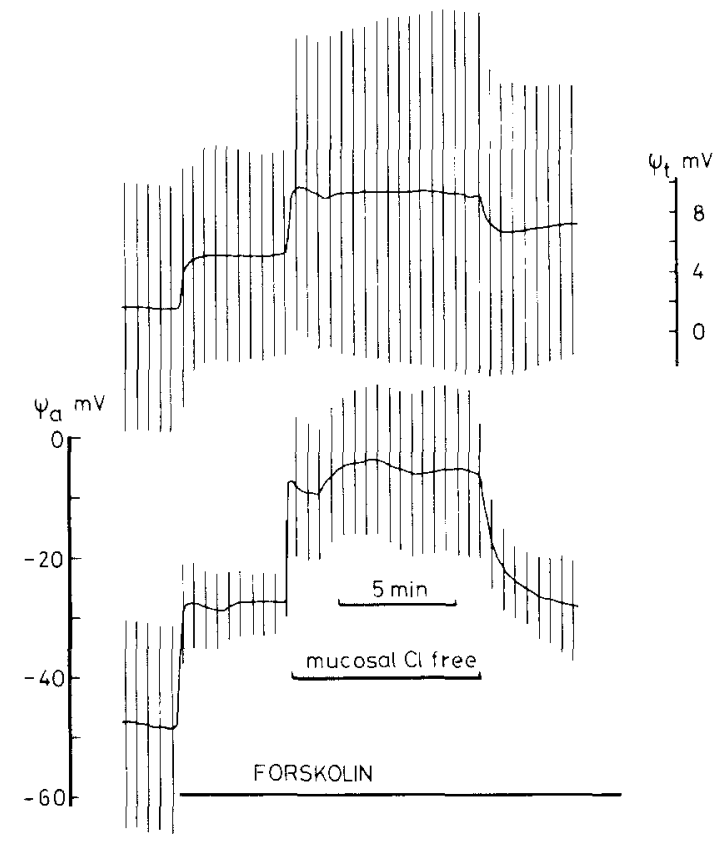

Fig. 3. Changes in transepithelial potential (upper tracing) and intracellular potential (lower tracing) induced by low $\mathrm{Cl}^{-}$Ringer's at the apical (mucosal) side in the presence of forskolin

increase after a few minutes, and after washout of forskolin, $R_{t}$ was higher than before forskolin. This phenomenon also affected the mean value of $R_{t}$.

The time course of the potential changes and the changes in the voltage deflections during the first 60 $\mathrm{sec}$ after the initiation of the response to forskolin was studied in more detail in 11 of these experiments performed on 5 monolayers. The experiments will be discussed in the section on electrical circuit analyses.

\section{INVOLVEMENT OF $\mathrm{Cl}^{-}$IN THE RESPONSE TO FORSKOLIN}

The prevalent idea is that the depolarization of the cell potential is driven by an electrogenic efflux of 
Table 2. Electrical parameters before and $3 \mathrm{~min}$ after addition of forskolin

\begin{tabular}{|c|c|c|c|c|c|c|c|c|c|c|c|c|}
\hline & \multicolumn{4}{|c|}{ Control } & \multicolumn{8}{|c|}{ Forskolin } \\
\hline & $\begin{array}{l}\Psi_{t} \\
\mathrm{mV}\end{array}$ & $\begin{array}{l}\Psi_{a} \\
\mathrm{mV}\end{array}$ & $\begin{array}{l}R_{t} \\
\Omega \mathrm{cm}^{2}\end{array}$ & $f R_{a}$ & $\begin{array}{l}\Psi_{t} \\
\mathrm{mV}\end{array}$ & $\begin{array}{l}\Psi_{a} \\
\mathrm{mV}\end{array}$ & $\begin{array}{l}R_{t t} \\
\Omega c \mathrm{~m}^{2}\end{array}$ & $f R_{u}$ & $\begin{array}{l}\Delta \Psi_{t} \\
\mathrm{mV}\end{array}$ & $\begin{array}{l}\Delta \Psi_{a} \\
\mathrm{mV}\end{array}$ & $\begin{array}{l}\Delta R_{t} \\
\Omega \mathrm{cm}^{2}\end{array}$ & $\Delta f R_{a}$ \\
\hline Mean & 1.3 & -50.1 & 138 & 0.80 & 5.2 & -23.9 & 111 & 0.22 & 3.9 & 26.1 & -25.6 & 0.58 \\
\hline SEM & 0.2 & 1.0 & 13 & 0.02 & $\begin{array}{c}0.4 \\
<0001\end{array}$ & $\begin{array}{l}0.7 \\
<0.001\end{array}$ & 12 & 0.01 & 0.4 & $\begin{array}{c}0.9 \\
<0001\end{array}$ & $\begin{array}{l}2.9 \\
<0001\end{array}$ & 0.01 \\
\hline
\end{tabular}

The data shown represent the mean \pm SEM of 58 experiments in 21 monolayers. $P$ values are with respect to control values or to zero in case of $\Delta$.

Table 3. Effect of forskolin in control and low $\mathrm{Cl}^{-}$Ringer

\begin{tabular}{|c|c|c|c|c|c|c|c|c|c|}
\hline & \multicolumn{4}{|c|}{-Forskolin } & \multicolumn{5}{|c|}{+ Forskolin } \\
\hline & $\begin{array}{l}\Psi_{1} \\
\mathrm{mV}\end{array}$ & $\begin{array}{l}\Psi_{a} \\
\mathrm{mV}\end{array}$ & $\begin{array}{l}R_{i} \\
\Omega \mathrm{cm}^{2}\end{array}$ & $f R_{a}$ & $\begin{array}{l}\Delta \Psi \\
\mathrm{mV}\end{array}$ & $\begin{array}{l}\Delta \Psi_{a} \\
\mathrm{mV}\end{array}$ & & $\begin{array}{l}\Delta R_{l} \\
\Omega \mathrm{cm}^{2}\end{array}$ & $\Delta f R_{u}$ \\
\hline Control & $1.1 \pm 0.2$ & $-53 \pm 1$ & $123 \pm 17$ & $0.85 \pm 0.01$ & $2.2 \pm 0.1$ & 25 & \pm 2 & $22 \pm 2$ & $0.58 \pm 0.04$ \\
\hline Low $\mathrm{Cl}^{-*}$ & $0.5 \pm 0.2$ & $-57 \pm 2$ & $172 \pm 23$ & $0.93 \pm 0.07$ & $-0.1 \pm 0.05$ & 1.0 & \pm 0.5 & $0 \pm 0$ & $0.01 \pm 0.01$ \\
\hline
\end{tabular}

The data shown represent the mean \pm SEM of five experiments.

* Changes induced by low $\mathrm{Cl}^{-}$occurred in all five experiments in the same direction.

Table 4. Changes in potential induced by low $\mathrm{Cl}^{-}$Ringer's in the apical compartment in the absence and presence of forskolin $\left(10^{-5} \mathrm{M}\right), n=7$

\begin{tabular}{lcr}
\hline & $\Delta \Psi_{f}(\mathrm{mV})$ & \multicolumn{1}{c}{$\Delta \Psi_{u}(\mathrm{mV})$} \\
\hline- Forskolin & $7.3 \pm 0.5$ & $5.9 \pm 0.4$ \\
+ Forskolin & $17.1 \pm 2.4$ & $34.5 \pm 1.5$ \\
$P$ & $<0.001$ & $<0.001$ \\
\hline
\end{tabular}

Data shown are means \pm SEM for seven experiments.

$\mathrm{Cl}^{-}$through cAMP-activated $\mathrm{Cl}^{-}$channels in the apical membrane. To study the participation of $\mathrm{Cl}^{-}$ in the forskolin response we perfused the monolayers with a saline in which all $\mathrm{Cl}^{-}$except for 0.1 $\mathrm{mm}$ was replaced by gluconate. During the incubation in the low $\mathrm{Cl}^{-}$solution the serosal perfusate was changed for a short period to a high $\mathrm{K}^{\dagger}$ gluconate saline $(\mathrm{K}=57 \mathrm{~mm})$ to probe the cell potential change induced by $\mathrm{K}^{+}$. Approximately $40 \mathrm{~min}$ after $\mathrm{Cl}^{-}$replacement forskolin was added.

Table 3 shows that under these conditions forskolin had no effect on the transepithelial or intracellular potential. Also, the fall in the fractional resistance of the apical membrane was totally absent in the low $\mathrm{Cl}^{-}$Ringer. These results strongly suggest that the forskolin response requires the presence of $\mathrm{Cl}^{-}$and suggest that the electrophysiological changes are related to $\mathrm{Cl}^{-}$-specific conductance increase in the apical membrane.
Table 5. Effect of NPPB $\left(10^{-5} \mathrm{M}\right)$ in the presence of forskolin

\begin{tabular}{lllll}
\hline & $\begin{array}{l}\Psi_{t} \\
\mathrm{mV}\end{array}$ & $\begin{array}{l}\Psi_{a} \\
\mathrm{mV}\end{array}$ & $\begin{array}{l}R_{i} \\
\Omega \mathrm{cm}^{2}\end{array}$ & $f R_{a}$ \\
\hline Control & $0.5 \pm 0.1$ & $-48 \pm 7$ & $135 \pm 12$ & $0.80 \pm 0.02$ \\
+ Forskolin & $3.5 \pm 0.3$ & $-25 \pm 4$ & $119 \pm 12$ & $0.26 \pm 0.07$ \\
+ Forskolin & $1.0 \pm 0.5$ & $-14 \pm 5$ & $147 \pm 19$ & $0.10 \pm 0.01$ \\
+ NPPB & & & &
\end{tabular}

The data shown represent the mean \pm SEM of three experiments. Values after forskolin were taken 5 min after addition. Values after NPPB were taken 2 min after addition.

If the depolarization is caused by the opening of $\mathrm{Cl}^{-}$channels in the apical membrane, one would expect that a change in the $\mathrm{Cl}^{-}$gradient should have a larger effect in stimulated as compared to resting conditions. This was tested by rapid changes of the apical perfusate from the normal Ringer's to the low $\mathrm{Cl}^{-}$Ringer's, in the absence or in the presence of forskolin in the basolateral perfusate.

Table 4 shows that the effects of apical $\mathrm{Cl}^{-}$substitution on potentials are significantly larger in the presence of forskolin.

Figure 3 shows the recording of a typical response of the potentials on apical $\mathrm{Cl}^{-}$replacement by gluconate in the presence of forskolin. Correction of this recording for liquid junction potentials across the salt bridge in the apical solution $(-9.5 \mathrm{mV})$ indicates that the intracellular potential actually becomes positive after $\mathrm{Cl}^{-}$replacement. A positive 
Table 6. Effect of bumetanide in the presence of forskolin

\begin{tabular}{lrrrr}
\hline & $\Psi_{i}(\mathrm{mV})$ & \multicolumn{1}{c}{$\Psi_{u}(\mathrm{mV})$} & $R_{i}\left(\Omega \mathrm{cm}^{2}\right)$ & \multicolumn{1}{c}{$f R_{a l}$} \\
\hline Control & $1.2 \pm 0.3$ & $-44.8 \pm 1.5$ & $215 \pm 10$ & $0.66 \pm 0.06$ \\
$\quad+$ forskolin & $4.7 \pm 0.7$ & $-22.2 \pm 1.8$ & $184 \pm 6$ & $0.16 \pm 0.05$ \\
$\quad \Delta$ & $3.5 \pm 0.5$ & $22.6 \pm 1.5$ & $-30 \pm 4$ & $-0.50 \pm 0.10$ \\
$\quad+$ forskolin + bumetanide & $1.8 \pm 0.6$ & $-38.6 \pm 4.0$ & $194 \pm 4$ & $0.26 \pm 0.06$ \\
$\quad \Delta$ & $-2.9 \pm 0.4$ & $-16.4 \pm 3.7$ & $9 \pm 4$ & $0.10 \pm 0.04$ \\
\hline
\end{tabular}

The data shown represent the mean \pm SEM of five experiments. Values after forskolin were taken 5 min after addition. Values after bumetanide were taken $30 \mathrm{~min}$ after addition.

potential is to be expected with a large $\mathrm{Cl}^{-}$conductance in the apical membrane and an outwardly directed chemical potential for $\mathrm{Cl}^{-}$.

\section{Putative $\mathrm{Cl}^{-}$-Channel Blockers}

The involvement of $\mathrm{Cl}^{-}$channels is often documented by their susceptibility to putative $\mathrm{Cl}^{-}$channel blockers like DPC and NPPB (Wangemann et al., 1986). The addition of these blockers to the apical solution in concentrations up to $10^{-6} \mathrm{M}$ were without measurable electrophysiological effects in the clone. At $10^{-5} \mathrm{M}$ and higher we observed a decrease of the transepithelial potential and a depolarization of the cell potential. Together with the decrease in $f R_{a}$ and increase in $R_{t}$ this indicates that the drugs had a pronounced effect on the basolateral membrane of the cells rather than on the apical $\mathrm{Cl}^{-}$conductance (see Table 5). Moreover, low $\mathrm{Cl}^{-}$Ringer in the apical compartment in the presence of NPPB and forskolin induced depolarizations not different from those reported in Table 4. These results contrast with published observations of $\mathrm{Cl}^{-}$channel inhibition in excised patches of the apical membrane of HT-29 cells (Hayslett et al., 1987), as well as with similar observations on excised patches of the clone $19 \mathrm{~A}$ in our own laboratory (unpublished results).

\section{EFFECT OF BUMETANIDE}

The depolarization of the apical membrane upon opening of a $\mathrm{Cl}^{-}$channel requires that the intracellular electrochemical potential of $\mathrm{Cl}^{-}$is higher than in the apical saline. In a number of epithelia the $\mathrm{Cl}^{-}$ accumulation is maintained by a $\mathrm{Na}^{+}$- and $\mathrm{K}^{+}$-dependent $\mathrm{Cl}^{-}$transport system which is bumetanide sensitive. The presence of this transport system in HT-29 cl.19A cells can be inferred from preliminary reports showing that bumetanide inhibits the $\mathrm{db}$ cAMP induced transepithelial potential change and $\mathrm{Rb}^{+}$transport and that bumetanide can be specifi- cally bound by these cells (Augeron et al., 1986; Augeron, Popowicz \& Simmons, 1987).

The effects of forskolin and subsequently bumetanide are shown in Table 6. Bumetanide $\left(10^{-4}\right.$ M) caused a slow repolarization of the cell potential to nearly the prestimulated value. Concomitantly, a small increase of the fractional resistance occurred.

\section{Potassium Permeability}

The observations so far fit well to a model for secretory epithelia postulating a $\mathrm{Cl}^{-}$-accumulating system in the basolateral membrane and $\mathrm{Cl}^{-}$channels in the apical membrane. As shown in several secreting epithelia, however, secretagogues may additionally induce an increase of the basolateral $\mathrm{K}^{+}$conductance resulting in a repolarization of the cell potential and maintenance of the driving force for $\mathrm{Cl}^{-}$excretion through the apical membrane. In the present experiments, however, no repolarization could be observed after the forskolin-induced depolarization. In addition, the fractional resistance stayed at the low level reached after forskolin. These observations suggest that in these cells the potassium conductance is not further increased by cAMP. However it may be that $R_{b}$ changed as fast as $R_{a}$, or in other words, that the change in potassium conductance is hidden by simultaneous but more dramatic changes in the apical $\mathrm{Cl}^{-}$conductance. In such a case the effect of opening of $\mathrm{K}^{+}$channels on $\Psi_{a}$ would be easier to observe in the absence of $\mathrm{Cl}^{-}$and would become manifest by a hyperpolarization and an increase of the apical fractional resistance. However, as shown in Fig. 4 and in the experiments already reported in Table 3, no hyperpolarization and no increase of fractional resistance was observed. In addition, the depolarization induced by the increase of the basolateral $\mathrm{K}^{\top}$ concentration was not larger in the presence of forskolin. These observations suggest that the sustained transepithelial current induced by forskolin can be maintained by the resting ionic conductance of the cells. 


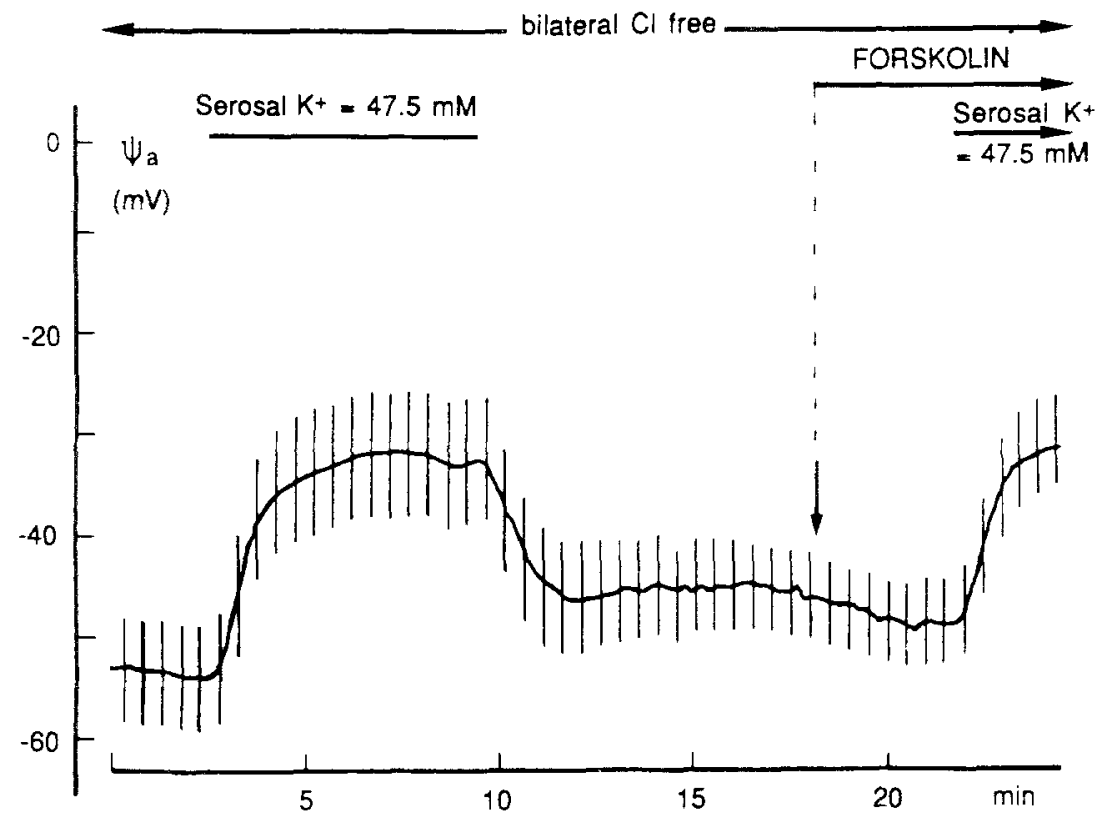

Fig. 4. Depolarizations induced by high $\mathrm{K}^{+}$solutions in the basolateral (serosal) compartment in the absence and presence of forskolin $\left(10^{-5} \mathrm{M}\right)$, and lack of effect of forskolin on the apical membrane potential in low $\mathrm{Cl}^{-}$Ringer's. This experiment is representative of four other experiments
Prime candidate for this conductance is the $\mathrm{Ba}^{2+}$-sensitive $\mathrm{K}^{+}$conductance in the basolateral membrane present in a number of $\mathrm{Cl}^{-}$-secreting epithelia. In two experiments we studied the effect of forskolin after preincubation of the monolayer for 10 min with $\mathrm{ImM} \mathrm{Ba}^{2+}$ at the basolateral side. $\mathrm{Ba}^{2+}$ alone induced a depolarization of the cell potential from -56 to $-30 \mathrm{mV}$ and a small decrease of the apical fractional resistance from 0.69 to 0.60 . The change in $G_{t}$ was statistically insignificant, and $\Psi_{t}$ decreased by $0.5 \mathrm{mV}$. The subsequent addition of forskolin further decreased the apical fractional resistance to 0.27 , whereas the cell potential showed a small further depolarization of $5 \mathrm{mV}$ to $-25 \mathrm{mV}$, and the transepithelial potential increased by only $0.5 \mathrm{mV}$.

In two other experiments the order of addition of $\mathrm{Ba}^{2+}$ and forskolin was reversed. In the presence of forskolin, $\mathrm{Ba}^{2+}$ decreased the transepithelial potential to $0.3 \mathrm{mV}$ above its pre-forskolin level, whereas the intracellular potential further depolarized with $5 \mathrm{mV}$ from $-24 \mathrm{mV}$ in the presence of forskolin to $-19 \mathrm{mV}$ in the combined presence of forskolin and $\mathrm{Ba}^{2+}$. These results corroborate the possibility that a basolateral $\mathrm{Ba}^{2+}$-sensitive $\mathrm{K}^{+}$conductance is necessary for the maintenance of the cAMP-induced transepithelial current.

The apparent insensitivity of the basolateral conductance to cAMP also appears from conventional equivalent electrical circuit analyses and opens the possibility to calculate the parameters of the circuit.

\section{Circuit Analyses}

Current pulses with a duration of $200 \mathrm{msec}$ were injected every second so that the change in $G_{t}$ and $f R_{\mathrm{i}}$ could be analyzed with a greater time resolution than shown in Fig. 2. The graphs in Fig. 5 show that the changes in $\Psi_{a}$ and $f R_{a}$ are at a maximum at about $20 \mathrm{sec}$ after the onset of the response to forskolin, whereas the maximum of $\Psi_{t}$ and $G_{t}$ was reached $30-40 \mathrm{sec}$ later.

The transepithelial conductance can be considered as two conductances in parallel, i.e., the transcellular conductance and the paracellular conductance. The transcellular conductance can be considered as the apical membrane conductance in series with the basolateral membrane conductance. In the course of this study we found that forskolin apparently had no effect on the basolateral membrane conductance. If in addition, the paracellular conductance does not change in the first period of the action of forskolin, then, a plot of $G_{t}$ versus $\left(1-f R_{a}\right)=f R_{b}$ would give a straight line with a slope of $G_{b}$ and an intersect of the ordinate representing $G_{p}$. In 10 out of 11 experiments we found a linear relation $G_{t}$ and $f R_{b}$ in the first period after the onset of the effect of forskolin. In one recording, not used further, the increase of $G_{t}$ took place after a time lag in which most of the change of the fractional resistance had already occurred.

In Fig. 6 the mean transepithelial conductance, relative to its value before stimulation of the monolayer, is plotted against the mean value of $f R_{b}$ for 

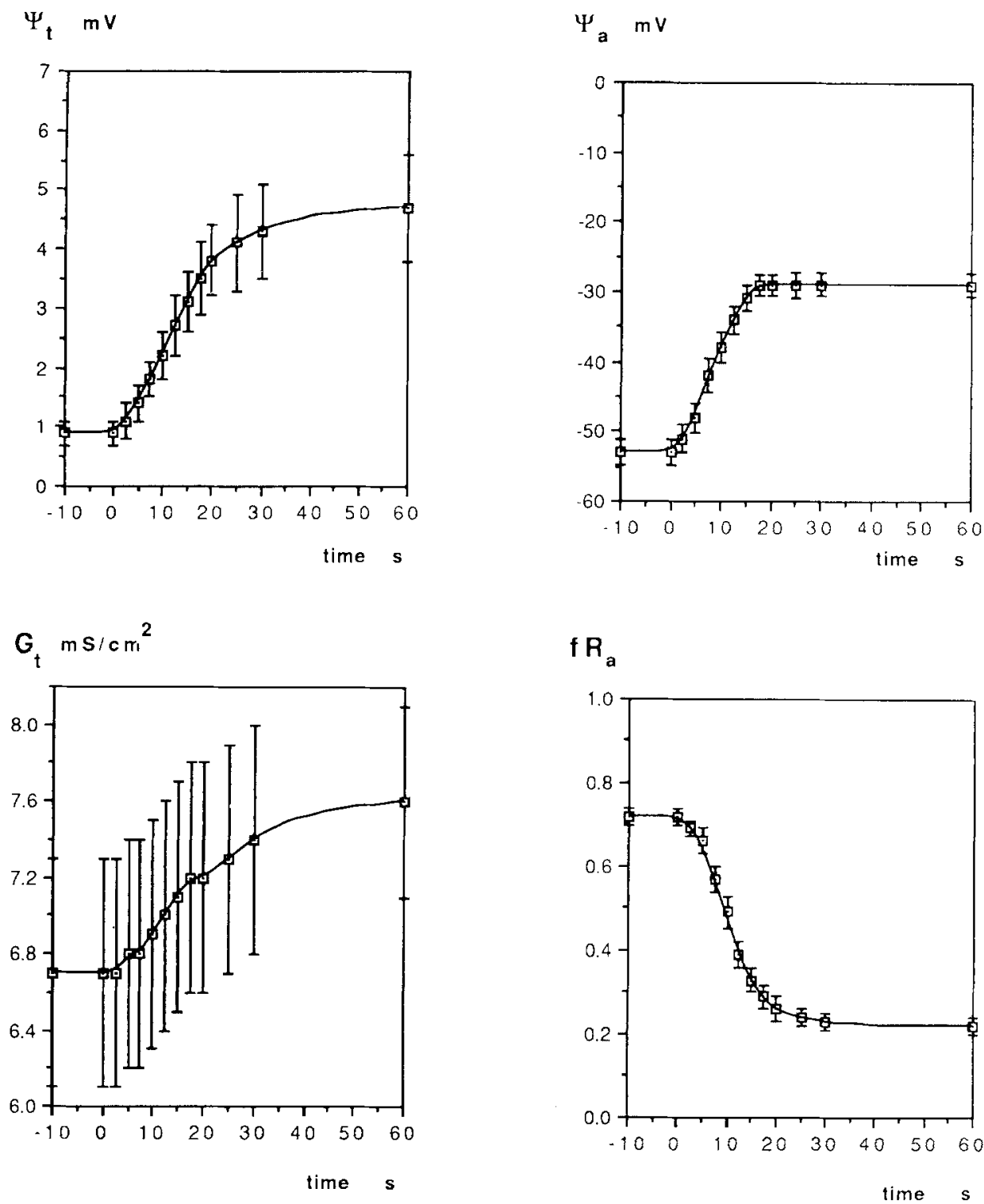

Fig. 5. Effect of forskolin on the potential difference across the apical membrane $\left(\Psi_{u}\right)$ (in $\mathrm{mV}$ ) and across the monolayer $\left(\Psi_{t}\right)$ (in $\mathrm{mV})$, the conductance of the monolayer $\left(G_{f}\right)$ and the fractional resistance of the apical membrane $\left(f R_{i}\right)$. Values were obtained from 11 cells from 5 monolayers. The bars represent SEM from 11 experiments

a period of $60 \mathrm{sec}$ after the onset of the forskolin response. The graph shows that after $20 \mathrm{sec}$ the change of $f R_{b}$ is virtually at a maximum while $G_{t}$ increased further. The mean value of the linear regressions through the points measured in the first 20 $\mathrm{sec}$ had a correlation coefficient of $0.96 \pm 0.01$. From the slopes and intersections $G_{b}$ and $G_{p}$ were estimated during the first $20 \mathrm{sec}$ after forskolin. $G_{b}$ was found to be $1.13 \pm 0.09 \mathrm{mS} / \mathrm{cm}^{2}$ and $G_{p}=6.26 \pm 0.65$ $\mathrm{mS} / \mathrm{cm}^{2}$ or $95 \%$ of the transepithelial conductance before forskolin addition.

Using the calculated values of $G_{b}$ and $G_{p}$ in the first $20 \mathrm{sec}$, the time course of the change in the apical membrane resistance $\left(R_{a}\right)$ in each experiment could be calculated. In Fig. 7 the mean values of $R_{u}$ are plotted against time. From the essentially stable value of $f R_{a}$ after $20 \mathrm{sec}$ and the absence of effect of forskolin on $f R_{a}$ in low $\mathrm{Cl}^{-}$Ringer's (see Table 3), it can be concluded that from this time point on $G_{c}$. may be considered constant, and therefore, the further increase in $G_{t}$ must result from a change in the paracellular conductance. On this basis values for $G_{p}$ from $25 \mathrm{sec}$ onwards were calculated. From the values of $G_{p}$ and the transepithelial potentials, the paracellular current, $I_{\mathrm{pc}}\left(=I_{\mathrm{tc}}\right.$ Eq. (4)), was calculated in the 10 individual experiments (Fig. 8). $E_{a}$ was 


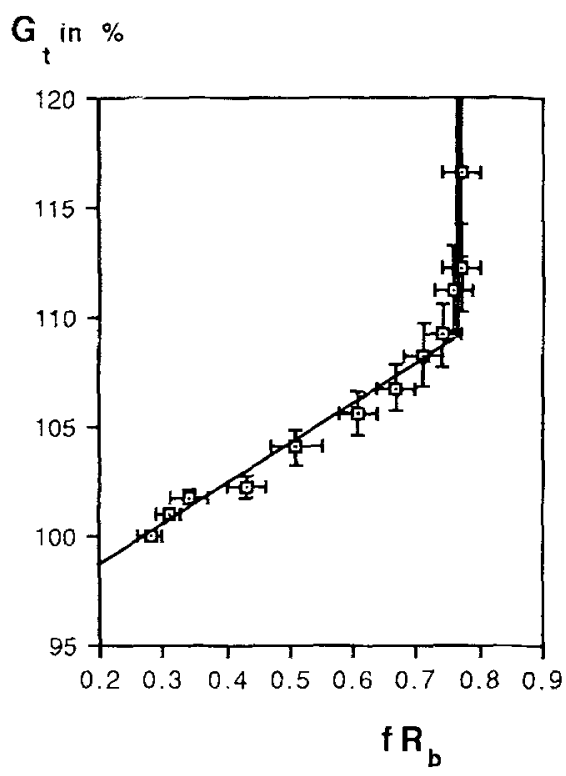

Fig. 6. Relation between relative transepithelial conductance $(G$, and fractional resistance of the basolateral membrane $\left(f R_{b}\right)$ during $60 \mathrm{sec}$ after forskolin addition. Mean values and SEM are from 10 experiments

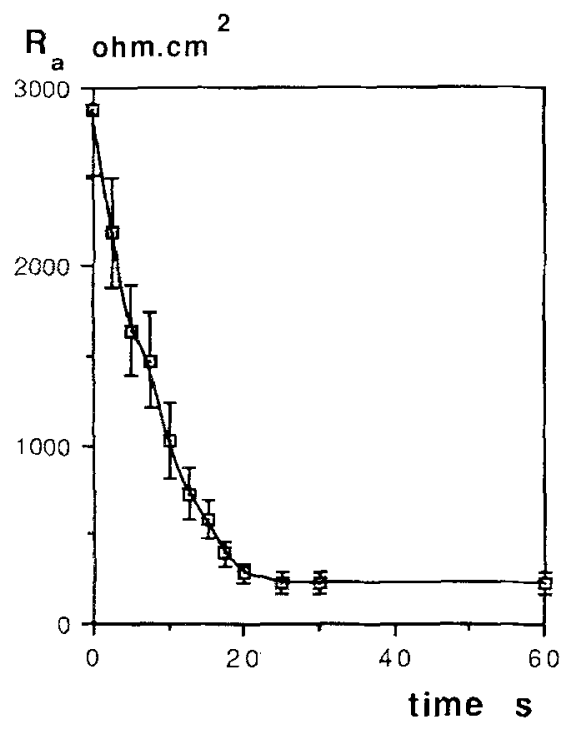

Fig. 7. Effect of forskolin on the apical membrane resistance $\left(R_{c}\right)$. Mean and SEM values are from 10 experiments

calculated according to Eq. (5). In three experiments these calculations gave ambiguous results in that $E_{a}$ at time zero was only $-18 \mathrm{mV}$, and thereafter, would oscillate around this value. The mean values of the seven other experiments are given in Fig. 9. It is suggested that addition of forskolin depolarizes $E_{a}$ from $-45 \pm 4 \mathrm{mV}$ to $-25 \pm 2 \mathrm{mV}$ at $t=20 \mathrm{sec}$ and to $-22 \pm 2 \mathrm{mV}$ at $t=60 \mathrm{sec}$.

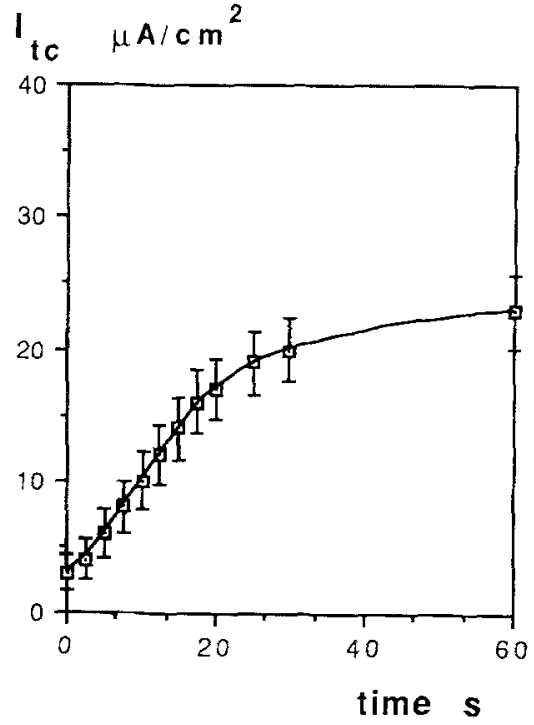

Fig. 8. Mean values and SEM for transcellular current calculated according to Eq. (4); $(n=7)$

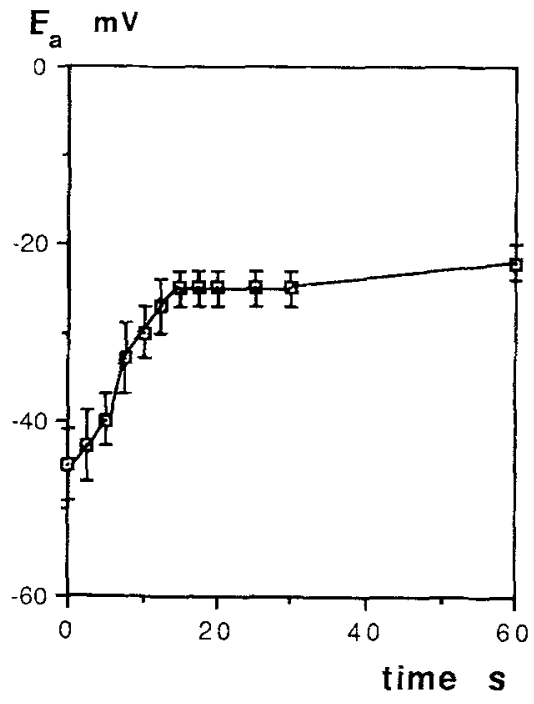

Fig. 9. Mean values and SEM of the electromotive force at the apical membrane calculated from $\mathrm{Eq},(5) ;(n=7)$

\section{Discussion}

\section{Basal Values of Electrical Parameters}

The monolayers formed by the HT-29 cl.19A human colon carcinoma cell line displayed transepithelial resistances that were generally lower than reported for $T_{84}$ cells (Dharmsathaphorn et al., 1985). However, the mean value of $119 \Omega \mathrm{cm}^{2}$ is in perfect agreement with the value of $114 \Omega \mathrm{cm}^{2}$ reported ear- 
lier for filter-grown cells of this subclone (Augeron et al., 1986). We observed a rather broad range of transepithelial resistances. Microscopic inspection of the monolayers did not reveal consistent morphological differences between monolayers with very high and very low resistances. After 7 days of culture $R_{t}$ did not correlate with age, neither did we observe a correlation between $R_{t}$ and the passage number. We presume that variations in $R_{t}$ may be due to differences in development of tight junctions, but we have not studied this assumption. A similar range of $R_{t}$ values has been found in Caco- 2 cells (Grasset et al., 1984). Moreover, the fractional resistances found in the present study are in perfect agreement with those measured earlier in the HT-29 clone (Augeron et al., 1986) and in domes of the Caco-2 cells (Grasset et al., 1985). The mean intracellular potential was somewhat lower than observed in the study of Augeron et al. (1986) and the transepithelial potential difference was slightly larger.

In a few monolayers, rather large transepithelial potential differences or serosa negative potentials were found while $R_{t}, \Psi_{a}$ and $f R_{a}$ were in the normal range. The origin of these variations in $\Psi_{t}$ was not further investigated. These monolayers were not used in the study of the forskolin response.

\section{EFFECTS OF FORSKOLIN ON THE \\ Electrical Parameters}

A consistent finding in this cell line was the large and sustained depolarization and sharp decrease in $f R_{a}$ in response to the serosal addition of forskolin. These effects of forskolin were observed only in the presence of $\mathrm{Cl}^{-}$. Moreover, the apical membrane potential was much more susceptible to a decrease of the $\mathrm{Cl}^{-}$concentration in the apical bath after addition of forskolin. This indicates that forskolin induced an increase of the $\mathrm{Cl}^{-}$conductance of the apical membrane and that the $\mathrm{Cl}^{-}$equilibrium potential is less negative than the cell potential. This requires that $\mathrm{Cl}^{-}$is electrochemically accumulated in the cells. The effects of bumetanide further suggest that $\mathrm{Cl}^{-}$may be accumulated via a $\mathrm{Na} / \mathrm{K} / 2 \mathrm{Cl} \mathrm{co}^{-}$ transport system. The sustained depolarization and reduction of $f R_{a}$ demonstrate that the conductance increase of the apical membrane is the predominant electrophysiological effect of forskolin. In our laboratory similar results have been obtained with $\mathrm{T}_{84}$ cells (Bajnath et al., 1989; R.B. Bajnath et al., in preparation). However, McRoberts et al. (1985) found that secretagogues induced an increase of the $\mathrm{Rb}^{+}$efflux and have suggested that cAMP may additionally open potassium channels in the basolateral membranes of $\mathrm{T}_{84}$ cells. We have tested the possibil- ity of a simultaneous increase in the apical and basolateral membrane conductances by depleting the cells from $\mathrm{Cl}^{-}$and adding forskolin afterwards. If forskolin also affected the basolateral $\mathrm{K}^{+}$conductance we would expect a hyperpolarization of $\Psi_{a}$ and an increase of $f R_{u}$. But neither of these parameters showed a significant change under these circumstances. A difficulty is that the incubation in $\mathrm{Cl}^{-}$free solution may have altered the cellular conditions in such a way that an extra $\mathrm{K}^{+}$conductance cannot be activated. However, $\mathrm{Ca}^{2+}$-related secretagogues (carbachol, ionomycin) induced a hyperpolarization and an increase of $f R_{a}$ under $\mathrm{Cl}^{-}$free conditions. Moreover, in $\mathrm{Cl}^{-}$-free solutions, a basolateral increase of $\mathrm{K}^{+}$induced a larger depolarization after stimulation with carbachol (R.B. Bajnath et al., submitted). This is in contrast with the smaller depolarization observed after forskolin. (The smaller depolarization as observed in Fig. 4 is a consequence of the forskolin-induced change in circuit parameters and does not indicate a decrease in basolateral $\mathrm{K}^{+}$ conductance.) Based on the responses to the $\mathrm{Ca}^{2+}$ related secretagogues in $\mathrm{Cl}^{-}$-free solutions, we conclude that it is not likely that in the low $\mathrm{Cl}^{-}$Ringer $\mathrm{K}^{+}$channel activation is inhibited.

In addition, analyses of $G_{t}$ versus $f R_{b}$ showed a linear relation during the first $20 \mathrm{sec}$, suggesting a decrease of $R_{a}$ only.

We postulate therefore that within the time scale of our experiments (up to $30 \mathrm{~min}$ after forskolin addition), cAMP failed to open $\mathrm{K}^{+}$channels in the basolateral membrane of the HT-29 cl.19A cells. In view of the similarity with the response of $\mathrm{T}_{84}$ cells we suggest that in this cell line as well, cAMP had no direct effect on the basolateral membrane conductance. This suggestion is in full accordance with recent observations (Cliff \& Frizzell, 1990). These authors showed that in $\mathrm{T}_{84}$ cells, voltage clamped at $E_{\mathrm{Cl}}$, forskolin did not change current, and they concluded that cAMP did not affect the $\mathrm{K}^{+}$current. As an explanation for the increased $\mathrm{Rb}^{+}$efflux we propose that this may be caused by the increased driving force generated by the depolarization of the apical membrane and the coupling of this change to the basolateral membrane due to the internal short circuiting in the monolayer via the low resistance paracellular pathway.

Although continuous impalements during $\mathrm{db}$ cAMP application have not been performed in the Caco-2 cell line (Grasset et al., 1985) their results also suggest a sustained depolarized state of $\Psi_{a}$ and sustained decrease of $f R_{a}$.

\section{COMPARISON With InTESTINAL EPITHElium}

These observations in cell lines contrast with the effect of db-cAMP and of $\mathrm{PGE}_{2}$ in rabbit colon (Welsh et al., 1982; Horvath et al., 1986) and of $\mathrm{PGE}_{2}$ 
in rat small intestine (Stewart \& Turnberg, 1989). In these tissues small and transient depolarizations were found. Because the transepithelial potential change was stable, one would expect that the repolarization of the cell potential is caused by a hyperpolarization of the basolateral membrane, presumably due to increased potassium conductance. However, in colon and small intestine $f R_{a}$ did not recover from its decrease.

It may be that the colon carcinoma cell lines have lost their ability to regulate the $\mathrm{K}^{+}$conductance in the basolateral membrane by cAMP or, alternatively, that this conductance is already maximally activated in the nonstimulated state. In contrast, we found positive evidence for activation of a basolateral $\mathrm{K}^{+}$conductance with carbachol, a $\mathrm{Ca}^{2+}$. mobilizing secretagogue (Bajnath et al., 1989).

On the other hand, it cannot be excluded that the transient depolarization in small and large intestinal cells is partially mediated by secretagogue-induced release of neurotransmitters or paracrinic signaling molecules (Groot et al., 1987).

In canine trachea, addition of epinephrine or $\mathrm{PGE}_{2}$ induced a transient depolarization of $\Psi_{a}$ and a transient decrease of $f R_{a}$, suggesting that these cAMP-related secretagogues affected the apical membrane as well as the basolateral membrane by increasing their conductances for $\mathrm{Cl}^{-}$and $\mathrm{K}^{+}$, respectively (Welsh, Smith \& Frizzell, 1983). However, recently it has been shown that cAMP can release $\mathrm{Ca}^{2+}$ from its intracellular stores in tracheal epithelial cells (McCann, Bhalla \& Welsh, 1989) and that this is sufficient to activate $\mathrm{K}^{+}$channels (McCann et al., 1990). In the HT-29 cl.19A cells. however, we could not detect a cAMP-induced increase of intracellular $\mathrm{Ca}^{2+}$ with fura-2 or indo 1 as intracellular $\mathrm{Ca}^{2+}$ probes (unpublished results).

\section{Requirements For a SUStained \\ ELECTROPHYSIOLOGICAL EFFECT OF ForsKolin}

The functional importance of the increase of the $\mathrm{K}^{+}$ conductance in the basolateral membrane is thought to be the maintenance of an electrochemical gradient for $\mathrm{Cl}^{-}$efflux through the apical membrane. An increase of the basolateral $\mathrm{K}^{+}$conductance may also be required to maintain the cellular homeostasis of $\mathrm{K}^{+}$because of a larger influx through a $\mathrm{Na} / \mathrm{K} / 2 \mathrm{Cl}$ cotransport system and the $\mathrm{Na} / \mathrm{K}$ pump. In the HT$29 \mathrm{cl} .19 \mathrm{~A}$ cells, however, the driving force for $\mathrm{K}^{+}$ efflux is increased as long as forskolin is present, and the basolateral conductance of about $1 \mathrm{mS} / \mathrm{cm}^{2}$ allows for an ohmic current of about $30 \mu \mathrm{A}$ at the basolateral membrane potential of about $-30 \mathrm{mV}$. This current is at the upper range of transcellular currents calculated from the present experiments.
Can this current be carried by $\mathrm{K}^{+}$? Assuming that the intracellular $\mathrm{K}^{+}$activity is not decreased, its driving force across the basolateral membrane in the presence of forskolin is augmented with about 30 $\mathrm{mV}\left(\Delta \Psi_{a}+\Delta \Psi_{t}\right)$. If the basolateral conductance reflects largely a $\mathrm{K}^{+}$conductance the current can indeed be carried by $\mathrm{K}^{+}$and it can provide for a sustained ion flux of about $1 \mu \mathrm{mol} / \mathrm{cm} \cdot \mathrm{hr}$. Flux measurements in the HT-29 cl. $19 \mathrm{~A}$ cells remain to be done, but the predicted value is in agreement with net $\mathrm{Cl}^{-}$fluxes found in the $\mathrm{T}_{84}$ cells (Dharmsathaphorn et al., 1985).

From the estimates of $R_{t i}$ and $I_{\mathrm{tc}}$ in the presence of forskolin it can be calculated that the electrochemical driving force required for the maintenance of the $\mathrm{Cl}^{-}$efflux is about $5 \mathrm{mV}$. Thus, the equilibrium potential for $\mathrm{Cl}^{-}\left(E_{\mathrm{Cl}}\right)$ should be about $5 \mathrm{mV}$ less negative than $\Psi_{a}$ during forskolin-induced $\mathrm{Cl}^{-}$secretion, or about $-20 \mathrm{mV}$. This value is nearly the same as the value calculated for $E_{a}(-22 \mathrm{mV})$, suggesting that $E_{a}$ is strongly dominated by $E_{\mathrm{Cl}}$.

With an extracellular $\mathrm{Cl}^{-}$concentration of 128.2 $\mathrm{mm}$ (activity $=93.5 \mathrm{~mm}$ ) this value of $E_{\mathrm{Cl}}$ would require that the intracellular activity is about $40 \mathrm{~mm}$ and can be maintained at that level in the presence of forskolin. The $\mathrm{Cl}^{-}$activity is in the range of activities reported for mammalian airway cells (Shorofsky, Field \& Fozzard, 1983; Willumsen, Davis \& Boucher, 1989). To our knowledge no intracellular $\mathrm{Cl}^{-}$ activities have been measured by direct techniques in the colon carcinoma cell lines. In the Caco-2 cells estimates of concentrations have been made recently, suggesting a resting concentration of $42 \mathrm{~mm}$ (Burnham \& Fondacaro, 1989).

The sustained character of the responses in the HT-29 cl.19A and $T_{84}$ cells suggests that the $\mathrm{Cl}^{-}$ cotransporter has a capacity that is sufficiently large to maintain the transcellular $\mathrm{Cl}^{-}$flux. The capacity can be estimated from bumetanide-sensitive $\mathrm{K}^{-}$influx studies in the HT-29 cl.19A cells and amounts to about $30 \mathrm{nmol} / 10^{6}$ cells $\cdot \min$ (Augeron et al., 1987). Assuming a cell density of $5 \times 10^{5}$ cells/ $\mathrm{cm}^{2}$ the influx would be equivalent to a sustained transcellular current of $24 \mu \mathrm{A} / \mathrm{cm}^{2}$. This value falls within the range measured in the present experiments.

\section{Cl Channel Blockers}

Further research is clearly needed to explain the anomalous effects of the putative $\mathrm{Cl}^{-}$channel blockers on HT-29 colonocytes (lack of effect on $\mathrm{Cl}^{-}$ conductance in intact cells and inhibitory action in excised membrane patches). The possibility that the NPPB- and DPC-sensitive $\mathrm{Cl}^{-}$channel in the excised patch is not related to the cAMP-activated 
$\mathrm{Cl}^{-}$conductance in the intact cell deserves special attention in view of its important consequences for the interpretation of the $\mathrm{Cl}^{-}$channel defect in cystic fibrosis patients (Kunzelmann, Pavenstadt \& Greger, 1989). The possibility that NPPB blocks $\mathrm{K}^{+}$ channels, and therefore, had similar effects as $\mathrm{Ba}^{2+}$ in inhibiting $\mathrm{Cl}^{-}$transport is also raised by the results of work of Diener and Rummel (1989) on rat colon.

\section{Paracellular Pathway}

The results also suggest that in addition to the large increase of the conductance of the apical membrane, an increase of the conductance of the paracellular pathway may occur as well. The paracellular conductance consists of the conductance of the tight junctions in series with the (presumably much larger) conductance of the lateral intercellular space. An increase of the tight junction conductance is in accordance with the VIP-induced increase of both unidirectional $\mathrm{Cl}^{-}$fluxes in $\mathrm{T}_{84}$ cells (Dharmsathaphorn et al., 1985) and the observation in fish intestine that cAMP increased the $\mathrm{Cl}^{-}$conductance of the paracellular pathway (Bakker \& Groot, 1989).

We would like to acknowledge the assistance of Klaas Dekker for taking care of the cell cultures used in this study. This work was supported by a grant from the Dutch Organization for Scientific Research, NWO.

\section{References}

Augeron, C., Laboisse, C.L. 1984. Emergence of permanently differentiated cell clones in a human colonic cancer cell line in culture after treatment with sodium butyrate. Cancer Res. 44:3961-3969

Augeron, C., Maoret, J.J., Laboisse, C.L., Grasset, E. 1986. Permanently differentiated cell clones isolated from the human colonic adenocarcinoma cell line HT29: Possible models for the study of ion transport and mucus production. In: Ion Gradient Coupled Transport. F. Alvarado and C.H. van Os, editors, pp. 363-366. Elsevier, Amsterdam

Augeron, C., Popowicz, P., Simmons, N.L. 1987. Bumetanide inhibition of ouabain-insensitive ${ }^{86} \mathrm{Rb}(\mathrm{K})$ transport in a cultured human colonic adenocarcinoma cell-line (HT29 cl.19A) J. Physiol. 391:100P (Abstr.)

Bajnath, R., Augeron, C., Maoret, J.J., Laboisse, C., de Jonge, H.R., Groot J.A. 1989. Comparison of electrophysiological changes induced by carbachol in $\mathrm{T}_{84}$ and HT-29 $\mathrm{cl} .19 \mathrm{~A}$ human colon carcinoma cell lines. Z. Gastroenterol. 27:287

Bakker, R., Groot J,A. 1989. Further evidence for the regulation of the tight junction ion selectivity by cAMP in goldfish intestinal mucosa. J. Membrane Biol. 111:25-35

Burnham, D.B., Fondacaro, J.D. 1989. Secretagogue-induced protein phosphorylation and chloride transport in $\mathrm{Caco}-2$ cells. Am. J. Physiol. 256:G808-G816

Cliff, W.H., Frizzell, R.A., 1990. Separate $\mathrm{Cl}^{-}$conductances activated by cAMP and $\mathrm{Ca}^{2+}$ in $\mathrm{Cl}^{-}$secreting epithelial cells. Proc. Natl. Acad. Sci. USA 87:4956-4960

Dharmsathaphorn, K., Mandel, K.G., Masui, H., McRoberts, J.A. 1985. Vasoactive intestinal polypeptide-induced chloride secretion by a colonic epithelial cell line: Direct participation of a basolaterally localized $\mathrm{Na}, \mathrm{K}, \mathrm{CI}$ cotransport system. $J$. Clin. Invest. 75:462-471
Diener. M., Rummel. W. 1989. Actions of the $\mathrm{Cl}^{-}$channel blocker NPPB on absorptive and secretory transport processes of $\mathrm{Na}^{-}$and $\mathrm{Cl}^{-}$in rat descending colon. Acta Physiol. Sicand. 137:215-222

Frizzell. R.A., Field, M., Schultz. S.G. 1979. Sodium-coupled chloride transport by epithelial tissues. Am. J: Physiol. 236: $F 1-F 8$

Grasset, E., Bernabeu, J.. Pinto. M. 1985. Epithelial properties of human colonic carcinoma cell line Caco-2: Effect of secretagogues. Am. J. Physiol. 248:C410-C418

Grasset, E.. Pinto, M.. Dussaulx, E., Zweibatum. A., Desjeux, J.F. 1984. Epithelial properties of human colonic carcinoma cell line Caco-2: Electrical parameters. Am. J. Physiol. 247:C260-C267

Groot. J.A., Bakker, R. 1988. $\mathrm{NaCl}$ transport in the vertebrate intestine. In: Advances in Comparative and Environmental Physiology. R. Greger, editor. Vol. 1, pp. 103-152. SpringerVerlag, Berlin

Groot, J.A., Bakker, R., Bijlsma, P., Oosterhuis, W.P. 1987. The response of stripped rat ileum to forskolin is partially mediated by neuronal cells. Z. Gastroenterol, 45:409 (Abstr)

Hayslett, J.P.. Gogelein, H., Kunzelman, K.. Greger. R. 1987. Characteristics of apical chloride channels in human colon cells (HT29). Pfluegers Arch. 410:487-494

Heintze, K. Stewart, C.P., Frizzell, R.A. 1983. Sodium dependent chloride secretion across rabbit descending colon. Am. J. Physiol. 244:G357-G365

Horvath, P.J., Fernandez, P.C., Weiser, M., Duffey, M.E. 1986. Localization of chloride secretion in rabbit colon: Inhibition by anthracene-9-carboxylic acid. Am. J. Physiol. 250: G185-G190

Kunzelmann, K., Pavenstadt. H., Greger, R. 1989. Properties and regulation of chloride channels in cystic fibrosis and normal airway cells. Pfuegers Arch. 415:172-182

McCann, J.D.. Bhalla, R.C., Welsh, M. 1989. Release of intracellular calcium by two different second messengers in airway epithelium. Am. J. Physiol. 257:L116-Ł124

McCann, J.D., Matsuda, J., Garcia, M., Kaczorowski, G.. Welsh, M. 1990. Basolateral $\mathrm{K}^{+}$channels in airway epithelia I. Regulation by $\mathrm{Ca}$ and block by charybdotoxin. Am. J. Physiol, 258:L334-L342

McRoberts, J.A., Beuerlein, G., Dharmsathaphorn, K. 1985. Cyclic AMP and $\mathrm{Ca}^{++}$activated $\mathrm{K}^{+}$transport in human colonic epithelial cell line. J. Biol. Chem. 260:14163-14172

Shorofsky. S.R., Field, M.. Fozzard, H.A. 1983. Electrophysiology of $\mathrm{Cl}^{-}$secretion in canine trachea. J. Membrane Biol. 72:105-115

Stewart. C.P.. Turnberg, L.A. 1989. A microelectrode study of responses to secretagogues by epithelial cells on villus and crypt of rat small intestine. Am. J. Physiol. 257:G334-G343

Wangemann, P., Di Stefano, A., Wittner, M., Englert, H.C., Lang, H.J., Schlatter, E., Greger, R. 1986. $\mathrm{Cl}^{-}$channel blockers in the thick ascending limb of the loop of Henle. Structure activity relationship. Pfluegers Arch. 407:S128-S141

Welsh, M.J. 1987. Electrolyte transport by airway epithelia. Physiol. Rev. 67:1143-1184

Welsh, M.J., Smith, P.L., Frizzell, R. 1983. Chloride secretion by canine tracheal epithelium: III. Membrane resistances and electromotive forces. J. Membrane Biol. 71:209-218

Welsh, M.J., Smith, P.L., Fromm, M., Frizzell, R.A., 1982. Crypts are the site of intestinal fluid and electrolyte secretion. Science 218: 1219-1221

Willumsen, N.J., Davis, C.W., Boucher, R.C. 1989. Intracellular $\mathrm{Cl}^{-}$activity and cellular $\mathrm{Cl}^{-}$pathways in cultured human airway epithelium. Am. J. Physiol. 256:C1033-C1044

Received 15 October 1990; revised 13 February 1991 